\title{
Study of Na-Montmorillonite-Polyamide Fiber/Polypropylene Hybrid Composite Prepared by Reactive Melt Mixing
}

\author{
Samia Kerakra, ${ }^{1}$ Said Bouhelal, ${ }^{1}$ and Marc Ponçot $^{2}$ \\ ${ }^{1}$ Unit of Emergent Research Materials, Ferhat Abbas Sétif 1 University, Setif, Algeria \\ ${ }^{2}$ Materials Science and Engineering-Metallurgy Department, Jean Lamour Institute, UMR 7198 CNRS, University of Lorraine, \\ Nancy, France \\ Correspondence should be addressed to Samia Kerakra; samiakerakra@gmail.com
}

Received 23 May 2017; Revised 28 August 2017; Accepted 25 September 2017; Published 30 October 2017

Academic Editor: Cornelia Vasile

Copyright (c) 2017 Samia Kerakra et al. This is an open access article distributed under the Creative Commons Attribution License, which permits unrestricted use, distribution, and reproduction in any medium, provided the original work is properly cited.

\begin{abstract}
Hybrid composites of polypropylene (PP)/sodium montmorillonite (Na-MMT)/short polyamide fibers (PAfs) were prepared by reactive melt mixing in a Brabender plastograph. To enhance filler interactions within polypropylene, a functionalizing agent (FA) and a coupling agent were added to the Na-MMT and PAfs, respectively. An organic peroxide/sulfur mixture and tetramethylthiuram disulfide as an activator for sulfur were used to functionalize Na-MMT; on the other hand, the PAfs surface was treated using stearic acid. The aim of this study is to investigate how the morphology and the structural properties of 3, 5, and $7 \mathrm{wt} \%$ recycled functionalized sodium montmorillonite nanocomposites (f-Na-MMT) are affected by the presence of $5 \mathrm{wt} \%$ treated short polyamide fibers (t-PAfs). According to the obtained results, $5 \mathrm{wt} \%$ recycled $\mathrm{f}-\mathrm{Na}-\mathrm{MMT} / 5 \mathrm{wt} \% \mathrm{t}-\mathrm{PAfs} / \mathrm{PP}$ hybrid composite showed $\mathrm{Na}-\mathrm{MMT}$ layers exfoliation. The nucleating effect of $\mathrm{f}-\mathrm{Na}-\mathrm{MMT}$ and $\mathrm{t}$-PAfs was indicated by the differential scanning calorimetry (DSC) measurements. Morphological analysis of the hybrid composites was performed using scanning electron microscope (SEM) and optical polarized microscopy (POM), showing a good dispersion of the fibers with an interesting interfacial adhesion between the PP and t-PAfs phases. Hybrid composites of PP/f-Na-MMT/t-PAfs are considered for automotive industry.
\end{abstract}

\section{Introduction}

The increasing demand in recent years for new lightweight, recyclable, and performing materials has guided the search for reinforced polymer systems [1]. Polymers are traditionally reinforced with synthetic or natural inorganic fillers in order to improve their properties and reduce their costs [2]. Commonly used fillers are clay, talc, mica $[3,4]$ and fibrouslike glass, carbon fibers, aramid, and jute fillers $[5,6]$. In order to improve or modify certain thermomechanical properties of polymers for specific applications, composites based on short fibers reinforced polymers find increasing applications in engineering and consumer products [7]. Increasing the adhesion between fiber and polymer matrix is one of the most effective ways to increase the degree of reinforcement by fibers [8]. Numerous studies have been reported concerning the enhancement of the interfacial interaction between the polymer/fibers phases [9-12]. On the other hand, nowadays we are witnessing increasing use of nanoscale composites that can enhance selected properties of related polymers [13]. Nanocomposites based on clay and layered silicates have been most widely investigated [14]. Montmorillonite (MMT) is one of the most used layered silicates. It is a 2:1 aluminosilicate, which is formed by two silica tetrahedral layers shared an octahedral sheet of aluminium or magnesium hydroxide [15, 16]. Stacked between the two layers is a regular Van der Waals gap called interlayer space or gallery.

Currently, the melt mixing is the most widely used method for preparing clay/PP nanocomposite $[16,17]$. The clay is incompatible with most polymers due to its strong hydrophilic character. Thus, a direct melt mixing of both components is not realizable. To overcome this difficulty, as a first step, the surface of the clay has to be modified by using an organophilic agent, thus giving rise to the socalled organophilic clay or organoclay $[18,19]$. On the work conducted by Kawasumi et al. [18], a new approach to prepare organoclay/PP nanocomposite has been reported, in which they expected to use a compatibilizer between the matrix and 
filler [19]. In that approach, nanocomposites were prepared by melt mixing due to its lower cost than the in situ polymerization method [20]. The research work of Toyota Company's research center developed the formation of organoclay/PP hybrid composites by direct melt mixing. The organoclay used in their study was montmorillonite (MMT), and the PP used was PP grafted with maleic anhydride (PP-g-MA) or hydroxyl groups with the aim of facilitating exfoliation and improving properties $[19,21]$.

Our laboratory developed a new route based on reversibly crosslinking reactive extrusion, which is applied for both the crosslinking of $\mathrm{PP}$ and the development of iPP/clay nanocomposites $[22,23]$. The developed method consists on the preparation of a functionalizing agent, capable of exfoliating the raw clay without any restricted working conditions; then the functionalized raw clay/PP nanocomposite was prepared by reactive melt mixing [24, 25]. Production of hybrid polymer composites systems based on fibers and nanoclay has shown recent achievements and activities. Eslami-Farsani et al. [26] studied the effect of nanoclay/basalt fiber on the mechanical properties of polypropylene. The authors proved that the presence of the layered structure in basalt fiber/propylene composite improved the interfacial adhesion of nanoclay and the fiber, therefore, improving the mechanical properties of composite. Chowdary and Kumar [27] analyzed the mechanical and morphological properties of nanoclay/S-glass fiber/polyester hybrid composite, in which they studied the effect of nanoclay content on S-glass fiber/polyester composite. The obtained results of their study showed that the incorporation of nanoclay had a significant effect on the mechanical behavior of composites. Several researches focused on this type of composites mainly processed by the combination of fiber with clay fillers in the same polymer matrix due to their easy availability and their low cost and also to enhance the physical and mechanical composites properties [28-30].

Development of hybrid composites based on polypropylene/clay/short polyamide fiber for the purpose of obtaining a lightweight and recyclable material which achieves strong interfacial interactions between filer and matrix, fiber dispersion, and clay layer exfoliation in PP matrix is the topic of this study.

The recycled 3, 5, and 7\% f-Na-MMT/5w t-\% PAfs/PP hybrid composites were prepared by reactive melt mixing in a Brabender plastograph. The microstructure and thermal properties of $\mathrm{f}-\mathrm{Na}$-MMT/t-PAfs/PP hybrid composites were studied. Fourier transform infrared (FTIR) and wideangle X-ray scattering (WAXS) were used to investigate the obtained hybrid structure. Morphological study of different composites was determined by scanning electron microscopy (SEM) and optical microscopy (OM). The melting and crystallization process of composites were tested by differential scanning calorimetry (DSC). The obtained results indicated that 5 wt $\%$ f-Na-MMT nanocompositions showed Na-MMT layers exfoliation, also a good dispersion of the treated fibers and an adhesion between the two polymer phases was observed. Automotive components (bumpers, stepassist) can be produced using f-Na-MMT/t-PAfs/PP hybrid composites; therefore, a mechanical study is recommended in order to test the mechanical properties of the obtained materials in this present study.

\section{Materials and Methods}

2.1. Materials. The commercial polypropylene SABIC RAFFIA 510P homopolymer was purchased from SABIC Arabie Saoudite. Its melt flow index (MFI) is $13.1 \mathrm{~g} / 10 \mathrm{~min}\left(230^{\circ} \mathrm{C}\right.$, $2.16 \mathrm{~kg}$ ). PA6 fiber was provided by Nanjing Forever Textile Co., Ltd. company, Jiangsu, China. Sodium montmorillonite Na-MMT, an unmodified nanoclay, was purchased from the Algerian region of Maghnia, supplied by ENOF, Algeria. The cation exchange capacity CEC of this montmorillonite is about $1.15 \times 10^{-3} \mathrm{~mol} / \mathrm{g}$. Dicumyl peroxide (DCP) (96 wt\% activity) was supplied by Sigma-Aldrich, France. Sulfur (S) (vulcanizing agent for rubber) was supplied by Wuxi Huasheng Chemical Additives Factory, China. The accelerator used was "Super accelerator 501" (tetramethylthiuram disulfide, TMTD), supplied by Rhône Poulenc, France.

2.2. Composites Preparation. The different composites were prepared in Brabender plastograph mixer using twin Roller blades at mixing temperature of $190^{\circ} \mathrm{C}$ and rotor speed of $60 \mathrm{rpm}$ during 20 minutes and, then, compressed into a dreher-type Brabender. The different composites were grinded before undergoing the diverse tests. The films were prepared by compression molding using a CARVAR manual press between hot plates at $200^{\circ} \mathrm{C}$ and at a pressure of $2 \mathrm{MPa}$ for $8 \mathrm{~min}$. A quench was applied to the films from the melt to room temperature.

2.2.1. f-Na-MMT/PP Nanocomposites Preparation. A series of composites have been studied consisting of different content of the f-Na-MMT (3, 5, and $7 \mathrm{wt} \%) / \mathrm{PP}$. Different composites were prepared using a conventional method [24]. Functionalizing agent (peroxide, sulfur, and accelerator)/dried $\mathrm{Na}-$ MMT were mixed together in the solid state, in which the functionalizing agent (FA) was added in a concentration of $1 / 10$ of the clay. The formulations are as follows: the sulfur concentration (in wt\%) was equal to that of peroxide, and the accelerator was $1 / 4$ of the sulfur or peroxide concentration.

PP was incorporated into the Brabender plastograph chamber firstly, and then the mixture Na-MMT/FA was introduced as soon as torque indicated melting of the polymer (about $2 \mathrm{~min}$ ).

Crosslinked PP (PP/1wt\% FA). The so-called "functionalizing agent of Na-MMT" which is constituted by the peroxide, sulfur, and accelerator was also used as crosslinking agent of PP [22]. Accordingly, an additional study of crosslinked PP has been done, with a view of evaluating and explaining the effect of functionalizing agents on the structure of PP. Also for understanding the effect of FA on neat PP structure, the same amount of functionalizing agent that was added to $\mathrm{Na}$ MMT was used to PP. The amount of sulfur and peroxide was 


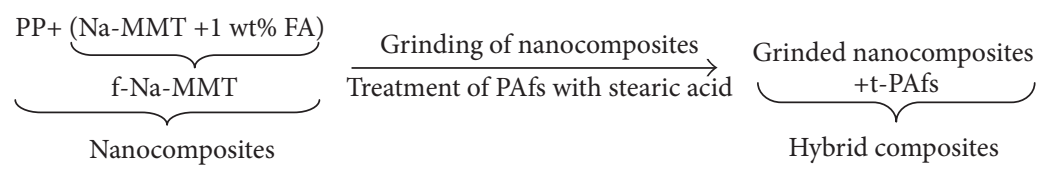

Scheme 1: The final obtained hybrid composites.

$1 \mathrm{wt} \%$ and the accelerator was $1 / 4$ of the sulfur and peroxide concentration.

\subsubsection{PAfs/PP Composites Preparation}

Surface Treatment of Polyamide Fibers (PAfs). Surface treatment of the polyamide fibers was carried out by stearic acid in order to increase the number of reactive groups and improve the fibers dispersion in $\mathrm{f}-\mathrm{Na}-\mathrm{MMT} / \mathrm{PP}$ nanocomposite. First of all, PAfs were chopped into about $4 \mathrm{~mm}$. Then, the obtained short fibers were washed with distilled water in order to remove the possible surface impurities and dried in vacuum oven at $60^{\circ} \mathrm{C} .25 \mathrm{mg}$ of stearic acid was dissolved in $200 \mathrm{ml}$ of toluene at ambient temperature by continuous magnetic stirring of solution for $20 \mathrm{~min}$. Then, $3 \mathrm{~g}$ of PA fibers was added to toluene/stearic acid solution under a magnetic stirring at ambient temperature for $12 \mathrm{~h}$ in order to complete the reaction between stearic acid with polyamide fibers surface and to improve the dispersion of the fibers into the solution. Following the treatment, PAfs were thoroughly washed with distilled water and dried in vacuum oven at $60^{\circ} \mathrm{C}$ for $8 \mathrm{~h}$.

Two series of PAfs/PP composites containing 5 wt $\%$ PAfs treated and untreated fibers were prepared. The fibers were dispersed in the PP pellets in the solid state; thereafter, the obtained mixture was inserted into Brabender plastograph chamber.

2.2.3. f-Na-MMT/PAfs/PP Hybrid Composites. PAfs/f-NaMMT/PP hybrid composites were prepared by adding $5 \mathrm{wt} \%$ of treated polyamide fibers ( $t$-PAfs) to different recycled nanocomposites 3, 5, and $7 \mathrm{wt} \% \mathrm{f}-\mathrm{Na}-\mathrm{MMT} / \mathrm{PP}$ which were prepared and grinded as it was explained above in the section of f-Na-MMT/PP nanocomposites preparation. Sample designation and composition of hybrid composites are presented in Table 1.

Scheme 1 shows the schematic processing steps of the hybrid composite preparation.

\section{Characterizations}

3.1. FTIR Measurements. FTIR spectra of film samples were recorded using a Perkin Elmer Spectrum 1000 spectrometer with a resolution of $4 \mathrm{~cm}^{-1}$ within 200 scans (PerkinElmer, USA). IR spectra were obtained for different composites film samples in the region from 400 to $4000 \mathrm{~cm}^{-1}$.

3.2. Wide-Angle X-Ray Scattering (WAXS). The crystalline structure was determined by WAXS analysis. WAXS profiles were recorded on a Seifert diffractometer (Rich. Seifert \& Co.,
TABLE 1: Sample designation and composition of hybrid composites.

\begin{tabular}{lcc}
\hline Sample & t-PAfs (wt\%) & $\begin{array}{c}\text { f-Na-MMT presented in PP } \\
\text { nanocomposite prepared (wt } \%)\end{array}$ \\
\hline $3 w t \%$ hyp & 5 & 3 \\
5 wt\% hyp & 5 & 5 \\
7 wt\% hyp & 5 & 7 \\
\hline
\end{tabular}

Germany). The following conditions were employed: $40 \mathrm{kV}$, $35 \mathrm{~mA}$, angular range of ${ }^{\circ} 4-35^{\circ}(2 \theta)$, and scan rate of $0.02^{\circ} / \mathrm{s}$.

3.3. Differential Scanning Calorimetry (DSC) Measurement. Thermograms of all composites were obtained using a Q200 instrument (TA Instruments, USA). The calorimetric runs were performed using $( \pm 10 \mathrm{mg})$ of each simple with a heating rate of $5^{\circ} \mathrm{C} / \mathrm{min}$. The samples were heated up to $200^{\circ} \mathrm{C}$ and maintained at this temperature during $5 \mathrm{~min}$ and then samples were cooled down to $25^{\circ} \mathrm{C}$ with a cooling rate $5^{\circ} \mathrm{C} / \mathrm{min}$. After that, a second heating was effectuated.

3.4. Optical Light Polarized Microscopy. Polarized light microscopy (Olympus bx50, USA) examinations were carried out on both sides of the cast samples.

3.5. Scanning Electron Microscope (SEM) Observation. The cross section of the tensile fractured surface of specimens was examined using an environmental scanning electron microscope (QUANTA- FEG 600, FEI Company, France).

\section{Results and Discussions}

4.1. Fourier Transform Infrared Spectroscopy (FTIR). Figure 1(a) shows the FTIR spectra of Na-MMT. The band at $3623 \mathrm{~cm}^{-1}$ produced from the $\mathrm{O}-\mathrm{H}$ stretching vibration associated with $\mathrm{Al}^{3+} \mathrm{Fe}^{2+}$ or $\mathrm{Mg}^{2+}$ cations. The intensive band situated at $1045 \mathrm{~cm}^{-1}$ was assigned to the $\mathrm{Si}-\mathrm{O}$ stretch, and that at $529 \mathrm{~cm}^{-1}$ is due to Si-O bending vibrations. The band at $1113 \mathrm{~cm}^{-1}$ was assigned to the $\mathrm{Si}$-O out-of-plane stretching vibration. The hydroxyl vibrations groups of water molecules showed two bands situated at 3440 and $1639 \mathrm{~cm}^{-1}$. The band at $798 \mathrm{~cm}^{-1}$ shows the quartz present in Na-MMT [31].

Figures 1(a), 1(b), and 1(c) display the FTIR spectra of different nanocomposites and crosslinked polypropylene (1 wt \% FA/PP). From the results presented in Figure 1(a), it was observed that the peak related to Na-MMT octahedral structure peak at $3623 \mathrm{~cm}^{-1}$ remained with a weak intensity in the spectra of 3 and $7 \mathrm{wt} \% \mathrm{f}-\mathrm{Na}-\mathrm{MMT} / \mathrm{PP}$; however, this peak disappeared with $5 \mathrm{wt} \% \mathrm{f}-\mathrm{Na}-\mathrm{MMT}$. In addition, weak peaks associated with the tetrahedral structure of Na-MMT 


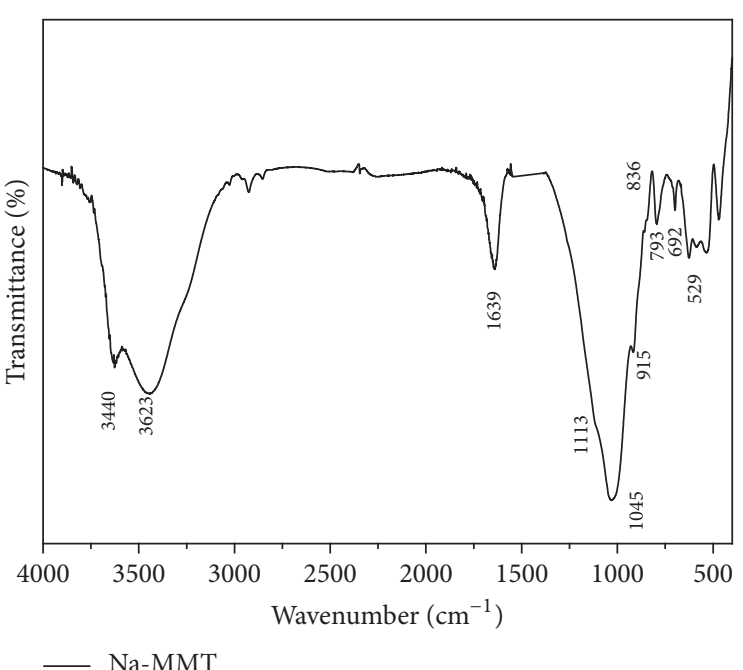

(a)

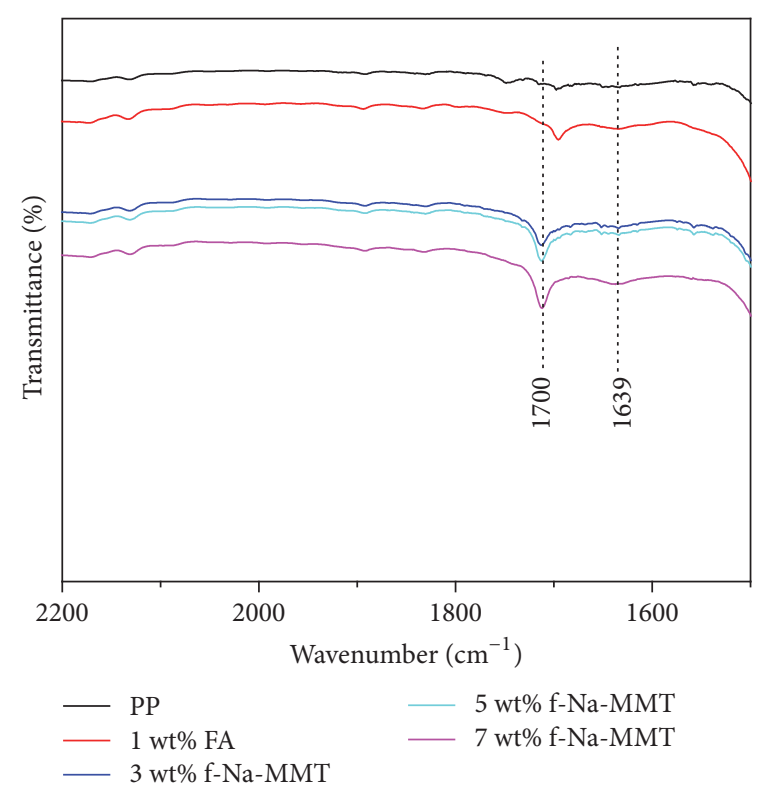

(c)

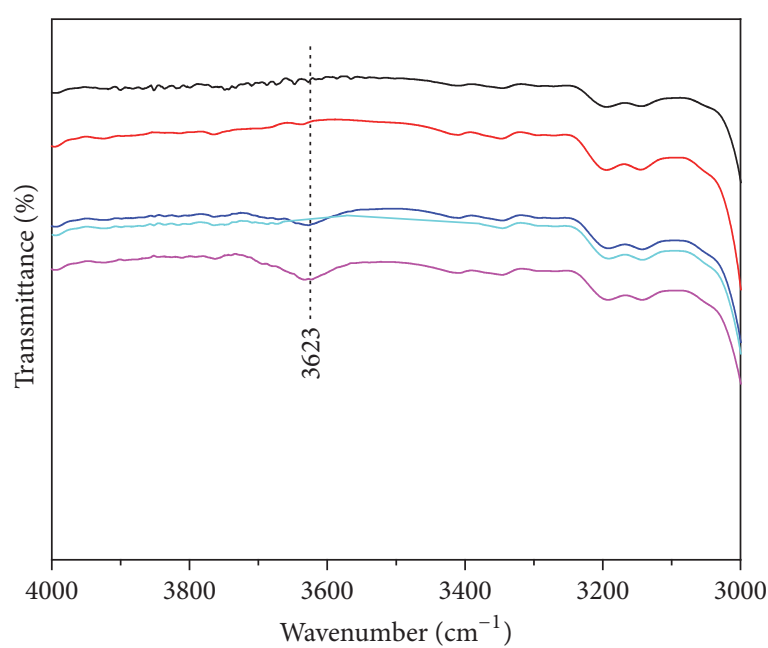

- PP $5 \mathrm{wt} \% \mathrm{f}-\mathrm{Na}-\mathrm{MMT}$

$1 \mathrm{wt} \% \mathrm{FA} \quad-7 \mathrm{wt} \% \mathrm{f}-\mathrm{Na}-\mathrm{MMT}$

- $3 \mathrm{wt} \% \mathrm{f}-\mathrm{Na}-\mathrm{MMT}$

(b)

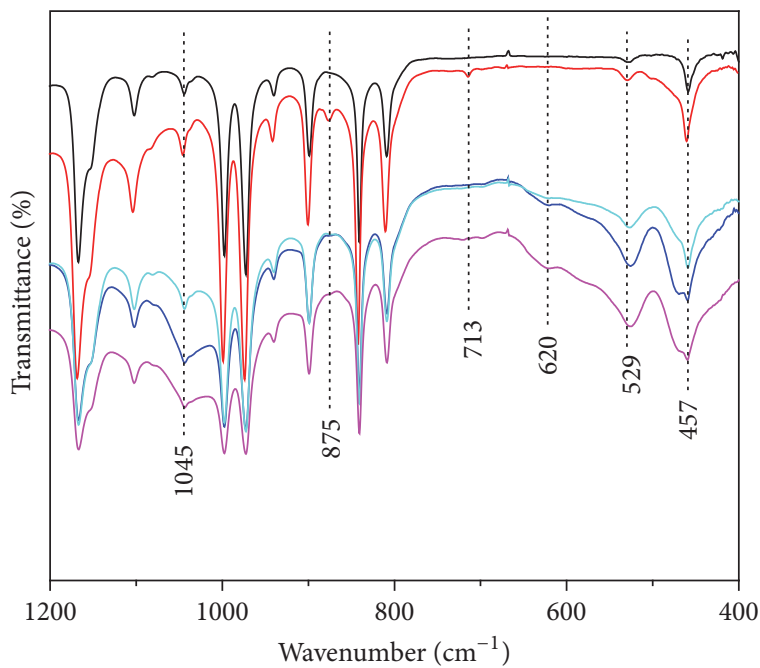

\begin{tabular}{ll}
- PP & $5 \mathrm{wt} \% \mathrm{f}-\mathrm{Na}-\mathrm{MMT}$ \\
\hline & $1 \mathrm{wt} \% \mathrm{FA}$
\end{tabular}

(d)

FIGURE 1: Fourier transform infrared spectroscopy (FTIR) spectra of (a) unmodified Na-MMT; (b, c, d) PP; PP/1 wt\% FA crosslinked PP; 3 , 5 , and $7 \mathrm{wt} \% \mathrm{f}-\mathrm{Na}-\mathrm{MMT}$ nanocomposites.

at $1639 \mathrm{~cm}^{-1}, 1045 \mathrm{~cm}^{-1}$, and at $529 \mathrm{~cm}^{-1}$ remained in the final structure of the different nanocomposites samples with strong intensities in the case of $\mathrm{PP} / 3$ and $7 \mathrm{wt} \% \mathrm{f}-\mathrm{Na}-\mathrm{MMT}$ as shown in Figures 1(b) and 1(c). This result can be explained by the reaction between the functionalizing agent used and $\mathrm{Na}$ MMT which is a redox reaction that involves the octahedral crystalline portion. Thus, the organometallic components of Na-MMT octahedral structure react in the presence of cations supplied by decomposition of the peroxide and the accelerator [32]. According to Bouhelal et al. [24], the technique of crosslinking by reactive extrusion that has been used in this present study gave rise to a partial or total exfoliation
( $4 \mathrm{wt} \%$ clay) with the absence of intercalated structure [25].

The different weak bands at $1700 \mathrm{~cm}^{-1}, 875 \mathrm{~cm}^{-1}$, $713 \mathrm{~cm}^{-1}$, and $620 \mathrm{~cm}^{-1}$ shown in Figures $1(\mathrm{c})$ and $1(\mathrm{~d})$ are related to crosslinked PP as observed in crosslinked PP spectrum. The band at $1700 \mathrm{~cm}^{-1}$ assigned to the carbonyl group $\mathrm{C}=\mathrm{O}$ which resulted from the reaction between the peroxide and $\mathrm{PP}$ and that at $875 \mathrm{~cm}$ due to the swinging of $\mathrm{N}-\mathrm{H}$ emerged from the reaction with the accelerator; the two bands at $713 \mathrm{~cm}^{-1}$ and $620 \mathrm{~cm}^{-1}$ attributed to C-S stretch that related to the reaction with the sulfur. From these results, we can conclude that a few a portion of the FA contributed 


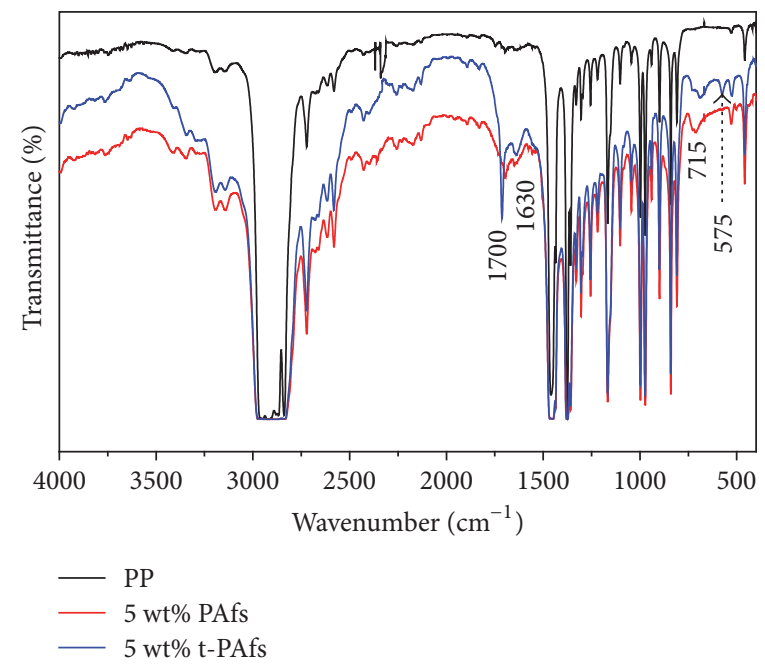

FIGURE 2: Fourier transform infrared spectroscopy (FTIR) spectra of PP, PP/5 wt $\%$ PAfs, and PP/5 wt $\%$ t-PAfs.

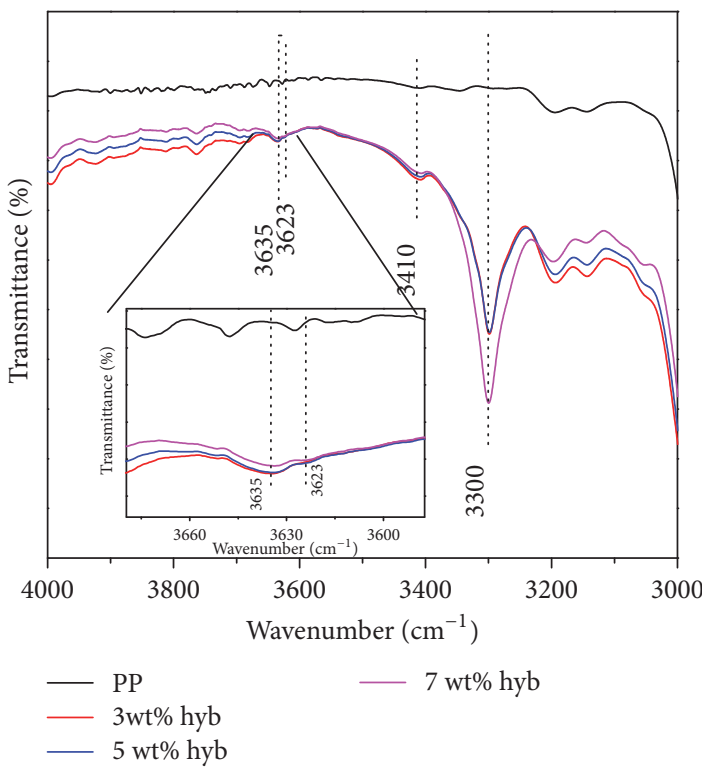

(a)

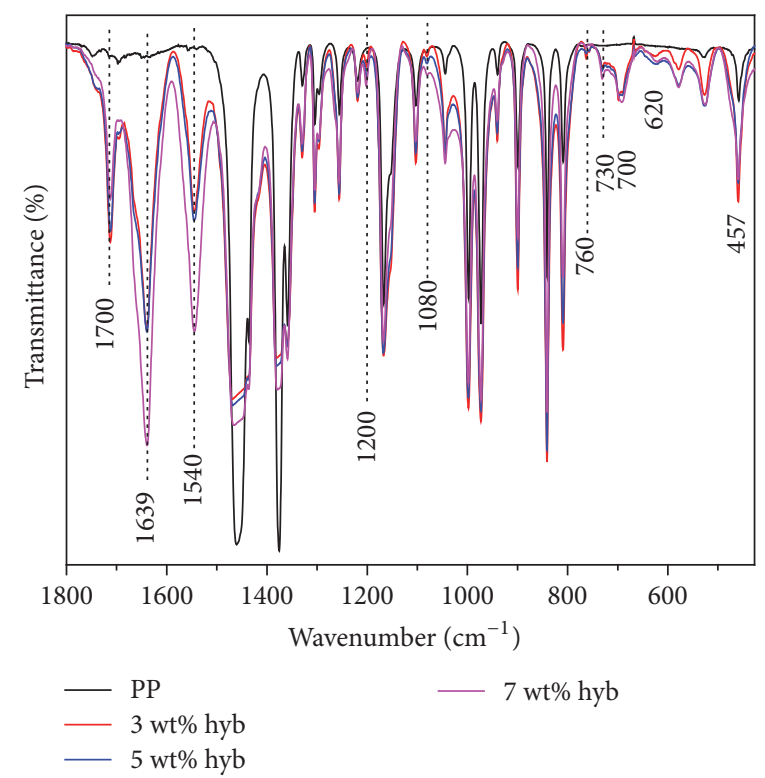

(b)

FIGURE 3: Fourier transform infrared spectroscopy (FTIR) spectra of (a, b) 5 wt $\%$ t-PAfs/3, 5, and 7 wt $\%$ f-Na-MMT/PP hybrid composites.

also in the chemical crosslinking process of PP, which was proved by the appearance of the $\beta$ and $\gamma$-crystalline forms in the WAXS patterns of crosslinked PP and $\mathrm{f}-\mathrm{Na}-\mathrm{MMT} / \mathrm{PP}$ nanocomposites.

Figure 2 displays the FTIR spectra of PP and different composites based on treated polyamide fibers (t-PAfs) and untreated polyamide fibers (PAfs) reinforced polypropylene (PP). Remarkable changes in intensities between the PP spectrum and the spectra of composites were seen. Both composites based on PA treated fibers and untreated fibers present a large absorption band in the interval $2960-2850 \mathrm{~cm}^{-1}$ which indicates the symmetric stretching vibration peak of $\left(-\mathrm{CH}_{2}{ }^{-}\right)$ group at 2850, and the absorption band of the asymmetric stretching vibration peak of $\left(-\mathrm{CH}_{2}^{-}\right)$group at $2919 \mathrm{~cm}^{-1}$. The absorption band at $2960 \mathrm{~cm}^{-1}$ is the antisymmetric stretching vibration peak of $-\mathrm{CH}_{3}$. The $\mathrm{t}-\mathrm{PAfs} / \mathrm{PP}$ composite shows new bands at 1700 and at $1630 \mathrm{~cm}^{-1}$ assigned to the stretching vibration peak of the carbonyl group $\mathrm{C}=\mathrm{O}$ in carboxylic acid and the combination absorbance of $\mathrm{C}=\mathrm{O}$ and $\mathrm{C}-\mathrm{N}$ amide $\mathrm{I}$ stretch. These new bands showed that FTIR spectra of treated polyamide are in good agreement with SEM observation of treated polyamide fiber, in which polyamide fibers exhibit rough surface.

FTIR spectra of PP and t-PAfs/f-Na-MMT/PP hybrid composites are shown in Figure 3. Different bands related to tetrahedral structure of Na-MMT were clearly observed in the spectra of all composites. Two characteristic weak bands of Na-MMT at $3635 \mathrm{~cm}^{-1}$ and at $3410 \mathrm{~cm}^{-1}$ related to the $\mathrm{OH}$ 


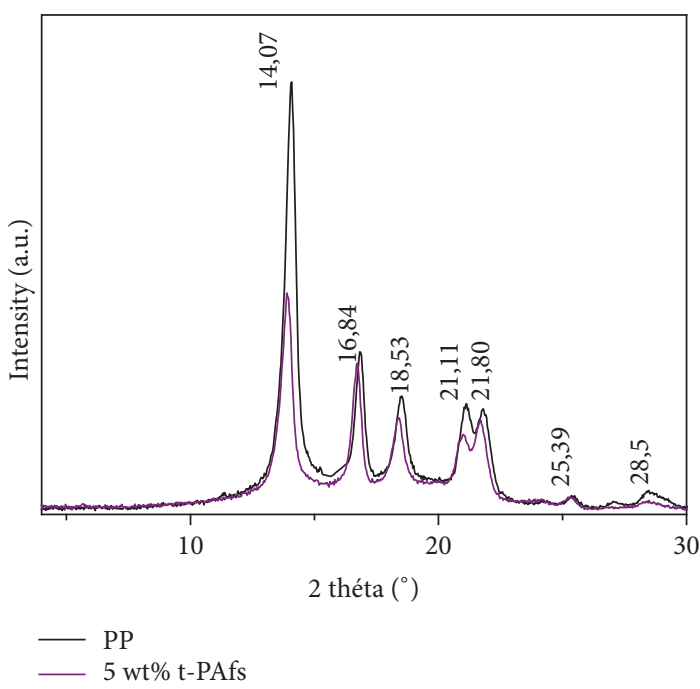

(a)

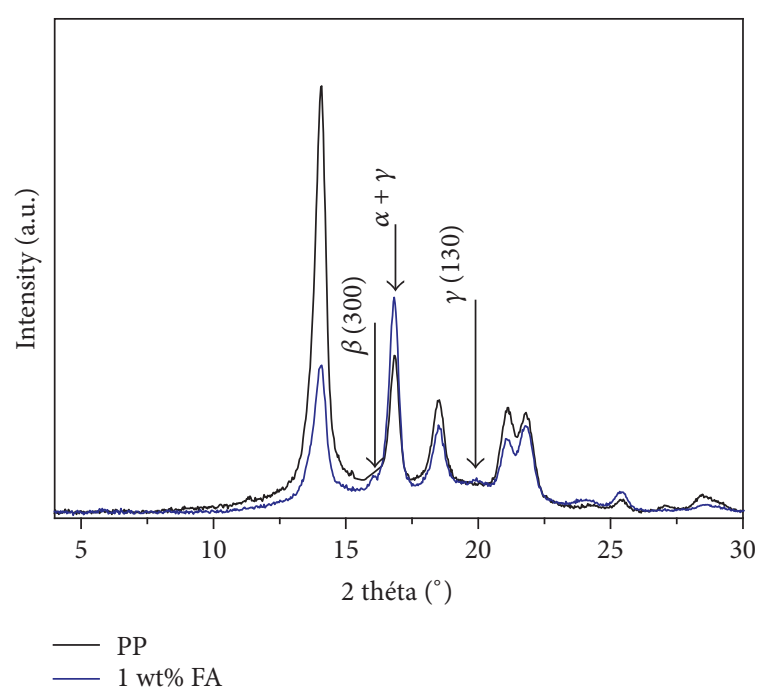

(b)

FIgURE 4: WAXS patterns of (a) $5 \mathrm{wt} \% \mathrm{t}-\mathrm{PAfs} / \mathrm{PP}$ composite and (b) $1 \mathrm{wt} \% \mathrm{FA} / \mathrm{PP}$ crosslinked PP.

of the $\mathrm{Al}-\mathrm{OH}$ and to the stretching and bending vibrations for the hydroxyl groups of water molecules were, respectively, shown. In addition, bands at 1639,692 , and $529 \mathrm{~cm}^{-1}$ associated with water molecules, quartz, and Si-O bending vibrations were, respectively, observed as seen in Figures $3(\mathrm{a})$ and 3(b). However, the band situated at $3623 \mathrm{~cm}^{-1}$ that attributed to Na-MMT octahedral structure disappeared in the FTIR spectra of all composites. The disappearance of the characteristic peaks of the Na-MMT octahedral layers from the FTIR spectra is in good agreement with the obtained FTIR results of $5 \mathrm{wt} \% \mathrm{f}-\mathrm{Na}-\mathrm{MMT} / \mathrm{PP}$ nanocomposite as has been discussed above, what led to confirm the exfoliation of the Na-MMT layers in PP with the presence of t-PAfs. Owing to the fact that the different nanocomposites were reprocessed in the second melt mixing cycle in which the polyamide fibers were added and that the characterizations were carried out in the samples which are able to be molten again and form films using compression molding, we can conclude that the recycled f-Na-MMT/PP nanocomposites have been successfully produced. Some bands associated with the crosslinked PP with FA as indicated above in crosslinked PP spectrum (Figures 1(b) and 1(c)) were further observed. The presence of the t-PAfs in $\mathrm{f}-\mathrm{Na}-\mathrm{MMT} / \mathrm{PP}$ nanocomposite matrix was proved by FTIR results, in which a new characteristic strong band at $3300 \mathrm{~cm}^{-1}$ of bending vibration in primary amine was observed in Figure 3(a), and three bands situated at $1700 \mathrm{~cm}^{-1}, 1540 \mathrm{~cm}^{-1}$, and $1200 \mathrm{~cm}^{-1}$ were assigned to the stretching vibration peak of the carbonyl group $(\mathrm{C}=\mathrm{O})$ in carboxylic acid, the combination absorbance of the $\mathrm{N}-\mathrm{H}$ and $\mathrm{C}-\mathrm{N}$ amide II stretch and $\mathrm{C}-\mathrm{N}$ stretch, respectively.

4.2. Wide-Angle X-Ray Scattering (WAXS). The structure of $\mathrm{PP} / 5 \mathrm{wt} \% \mathrm{t}$-PAfs was evaluated by a wide-angle X-ray scattering method. On the basis of the WAXS patterns are shown in Figure 4(a). Only characteristic peaks of $\alpha$ form PP

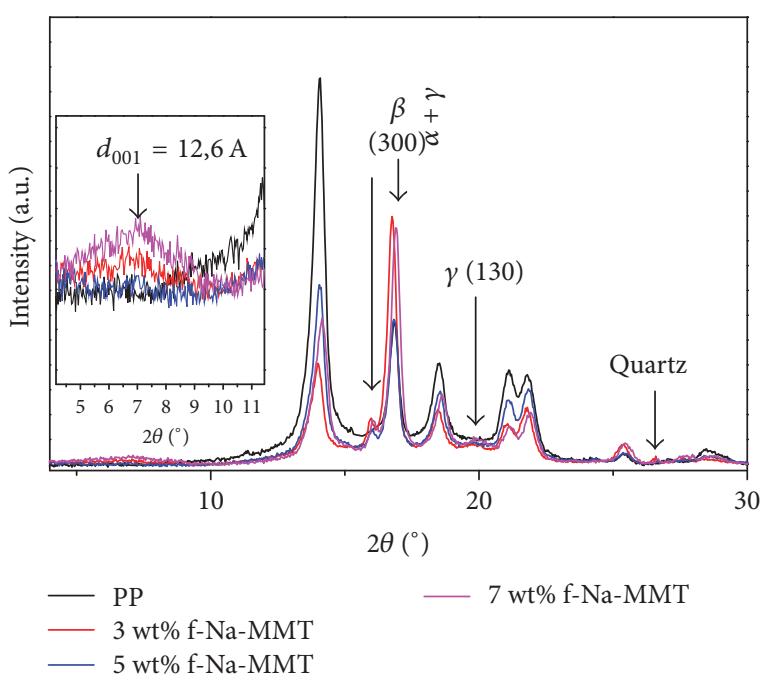

FIGURE 5: WAXS patterns of 3, 5, and 7 wt $\% / P P$ nanocomposites.

can be found, which can be indexed as $(110)$ at $2 \theta\left(^{\circ}\right)=14.07$, $(040)$ at $16.84,(130)$ at $18.5,(111)$ at 21.11 , and (041) at 21.8 and (060), (220) at about 25.3 and 28.5, respectively, without any additional diffraction peaks.

The effect of FA on the structure of PP has been studied. Crosslinked PP is shown in Figure 4(b). The WAXS pattern shows two new weak peaks at 16.2 and $20.1(2 \theta)$ which are characteristic of the (300) planes of PP $\beta$-crystalline form and the (130) or (117) planes of the $\gamma$-crystalline, respectively. It can be seen also in Figure 4(b) that the intensity of the reflection at $16.7(2 \theta)$ is higher than that of PP which is due to the appearance of the $\gamma$-crystalline form in the crosslinked $\mathrm{PP}$, as both $\alpha$ - and $\gamma$-forms show a reflection in this position.

Figure 5 shows the X-ray diffraction patterns of 3, 5, and $7 \mathrm{wt} \% \mathrm{f}-\mathrm{Na}-\mathrm{MMT} / \mathrm{PP}$ nanocomposites. From this figure it 


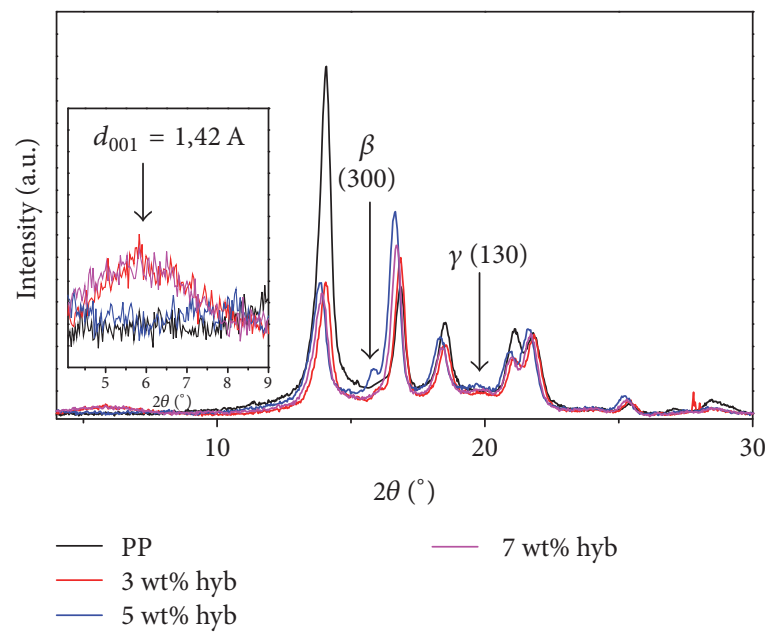

FIGURE 6: WAXS patterns of $5 \mathrm{wt} \% \mathrm{t}$-PAfs/3, 5, and $7 \mathrm{wt} \% \mathrm{f}-\mathrm{Na}-\mathrm{MMT} / \mathrm{PP}$ hybrid composites.

was observed that the WAXD patterns exhibit the typical reflections of the $\alpha$-form of PP, with four additional peaks, at $6.9,16.2,20.1$, and $26.7(2 \theta)$ that are characteristic of the $\mathrm{d}_{001}$ spacing of Na-MMT, (300) planes of the iPP $\beta$-crystalline form, (130) or (117) planes of the $\gamma$-crystalline form, and the quartz accompanying the Na-MMT which was shown with much less intensity. The characteristic peak of the $\mathrm{d}_{001}$ spacing of Na-MMT, indicated by an arrow, appeared with a weak intensity in 7 and $3 \mathrm{wt} \% \mathrm{f}-\mathrm{Na}-\mathrm{MMT}$. However, it disappeared in the case of PP with $5 \mathrm{wt} \% \mathrm{f}-\mathrm{Na}-\mathrm{MMT}$. According to Giannelis et al. $[16,33]$ the disappearance of peak indicates the separation of clay layers (exfoliated structure) and the formation of nanocomposites. The two new peaks at 16.2 and 20.1 have been already presented in the diffractogram of the crosslinked sample having no Na-MMT (Figure 4(b)). On the work conducted by Bouhelal et al. [24] based on the development of iPP/clay nanocomposites, it was found that $4 \mathrm{wt} \%$ clay gave a rise to a partial or total exfoliation in which the reactive extrusion technique was used. Further, in this present study the exfoliation of the Na-MMT layers was given with $5 \mathrm{wt} \% \mathrm{f}-\mathrm{Na}-\mathrm{MMT}$.

Figure 6 displays the WAXS patterns of t-PAfs/f-Na$\mathrm{MMT} / \mathrm{PP}$ hybrid composites. It was observed that the presence of PAfs with Na-MMT do not give any significant difference compared with the WAXS patterns of nanocomposite (Figure 5). The same additional peaks are shown, with the disappearance of the weak peak assigned to the quartz in nanocomposites samples and the peak related to $\beta$-crystalline form at 16.2 in $7 \mathrm{wt} \% \mathrm{t}$-PAfs/f-NaMMT hybrid. Also, it can be seen that the characteristic peak of the $\mathrm{d}_{001}$ spacing of Na-MMT shifted to higher diffraction angles unlike the diffraction angle of Na-MMT which was found in the PP/Na-MMT nanocomposites. The exfoliation of the Na-MMT layers was given with $5 \mathrm{wt} \% \mathrm{f}-$ Na-MMT also as it has been explained above in the Xray diffraction patterns of $\mathrm{f}-\mathrm{Na}-\mathrm{MMT} / \mathrm{PP}$ nanocomposites (Figure 5).

From the WAXS patterns, the degree of crystallinity $\left(\chi_{c}\right)$ can be measured using the following equation [34]:
TABLE 2: WAXS measurements: ( $\chi_{c}^{\text {WAXs }}$ ), $X_{\beta}$ of $\beta$ form and $X_{\gamma}$ of the $\gamma$-form.

\begin{tabular}{lccc}
\hline Sample & $X_{\beta}$ & $X_{\gamma}$ & $\chi_{c}{ }^{\text {WAXS }}(\%)$ \\
\hline PP & - & - & 38.1 \\
5 wt\% t-PAfs/PP & - & - & 32.6 \\
1 wt\% FA/PP & 0.010 & 0.32 & 36 \\
3 wt\% Na- MMT & 0.017 & 0.50 & 37.7 \\
5 wt\% Na-MMT & 0.016 & 0.53 & 38 \\
7 wt\% Na- MMT & 0.02 & 0.55 & 38.2 \\
3 wt\% hyb & 0.016 & 0.36 & 38 \\
5 wt\% hyb & 0.016 & 0.45 & 38.5 \\
7 wt\% hyb & - & 0.36 & 38 \\
\hline
\end{tabular}

$$
\chi_{c}^{\text {WAXS }}=\frac{I_{c}}{\left(I_{a}+I_{c}\right)}
$$

where $I_{c}$ and $I_{a}$ present the integrated intensities of crystalline and amorphous phases, respectively, which were determined by deconvolutions of WAXS patterns.

We have also estimated the content $X_{\beta}$ of $\beta$ form and $X_{\gamma}$ of the $\gamma$-form in all the studied samples according to the method of Jones et al. [35, 36] (Table 2):

$$
\begin{aligned}
& X_{\gamma}=\frac{I^{\gamma}{ }_{(130)}}{\left(I^{\gamma}{ }_{(130)}+I^{\alpha}{ }_{(130)}\right)}, \\
& X_{\beta}=\frac{I^{\beta}{ }_{(300)}}{\left(I^{\alpha}{ }_{(110)}+I^{\alpha}{ }_{(040)}+I^{\alpha}{ }_{(130)}+I^{\alpha}{ }_{(300)}\right)} .
\end{aligned}
$$

The obtained degree of crystallinity $\left(\chi_{c}\right), X_{\beta}$, and $X_{\gamma}$ are collected in Table 3 . It is clearly observed that the degree of crystallinity $\left(\chi_{c}\right)$ seems to be relatively constant with the different composites (nanocomposites and hybrid composites) in comparison with the neat iPP; however, it is lower in the case of $\mathrm{t}-\mathrm{PAf} / \mathrm{PP}$. The degree of crystallinity of different composite is consistent with DSC results. 
TABLE 3: Melting $\left(T_{m}\right)$, crystallization temperatures $\left(T_{c}\right)$, and enthalpies $\left(\Delta H_{m}, \Delta H_{c}\right)$ for different samples and crystallinity degree $\left(\chi_{c}\right)$ obtained by DSC.

\begin{tabular}{|c|c|c|c|c|c|}
\hline Sample & $\begin{array}{c}\Delta H_{m} \\
(\mathrm{~J} / \mathrm{g}) \\
\end{array}$ & $\begin{array}{c}T_{m} \\
\left({ }^{\circ} \mathrm{C}\right) \\
\end{array}$ & $\begin{array}{l}\Delta H_{c} \\
(\mathrm{~J} / \mathrm{g}) \\
\end{array}$ & $\begin{array}{c}T_{c} \\
\left({ }^{\circ} \mathrm{C}\right) \\
\end{array}$ & $\chi_{c}{ }^{\mathrm{DSC}}(\%)$ \\
\hline $\mathrm{PP}$ & 90 & 161 & 98 & 116 & 42.4 \\
\hline $\mathrm{PP} / 5 \mathrm{wt} \% \mathrm{t}-\mathrm{PAfs}$ & 77 & 159 & 89 & 117.5 & 39 \\
\hline 3 wt $\%$ Na-MMT & 87.9 & 158.3 & 98.3 & 120 & 43.6 \\
\hline 5 wt $\%$ Na-MMT & 83.7 & 158.5 & 98 & 120.8 & 42.3 \\
\hline 7 wt $\%$ Na-MMT & 81.7 & 160 & 92.5 & 119.5 & 42.1 \\
\hline 3 wt $\%$ hyb & 87.7 & 159.5 & 102.3 & 120 & 45.6 \\
\hline 5 wt $\%$ hyb & 83.5 & 159.3 & 102.1 & 120.3 & 44.7 \\
\hline 7 wt $\%$ hyb & 83.1 & 159.5 & 100.1 & 121.4 & 45.2 \\
\hline
\end{tabular}
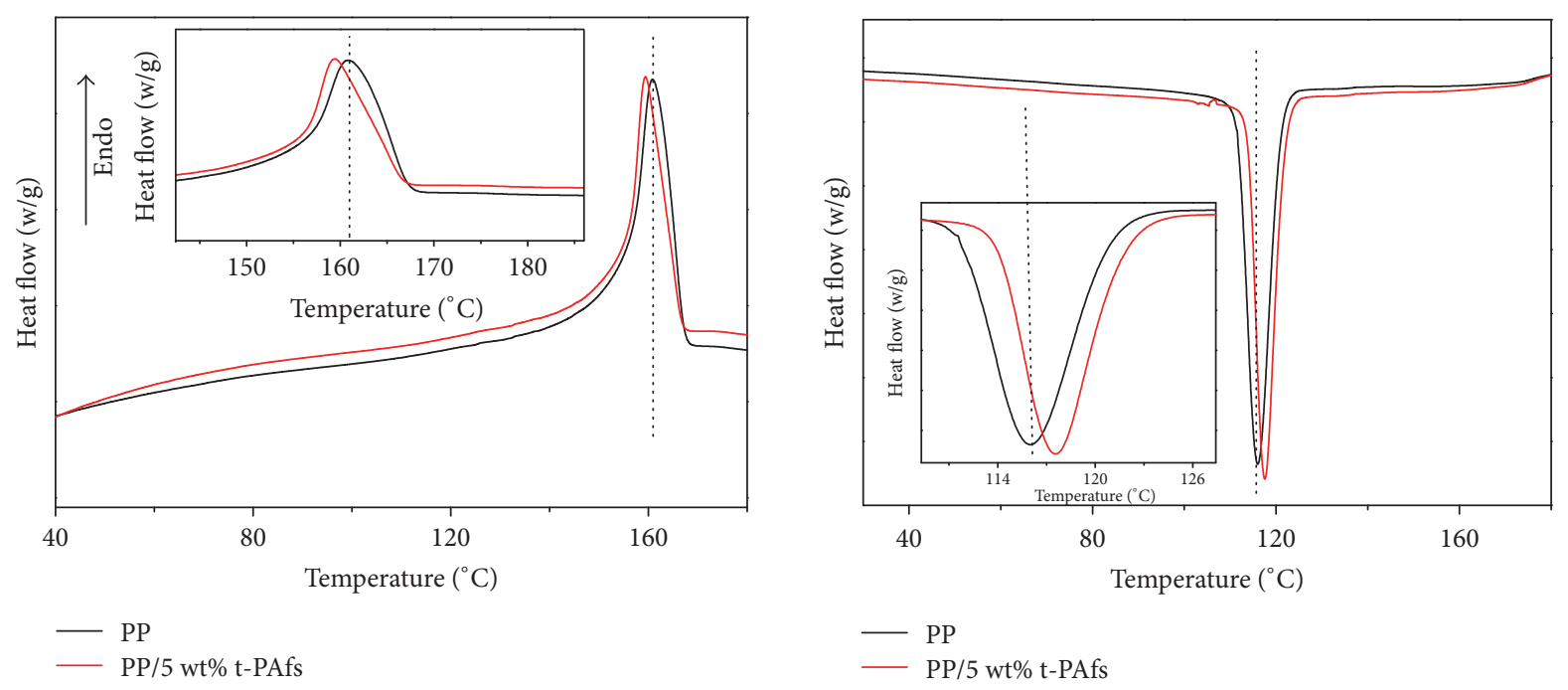

FIGURE 7: DSC thermographs of second heating and cooling runs of $5 \mathrm{wt} \% \mathrm{t}-\mathrm{PAfs} / \mathrm{PP}$ composite.

A gradual increase of $X_{\gamma}$ value has been noted in different nanocomposite samples. It increases from 0.32 in the crosslinked PP, up to 0.55 for the samples with $3-7 \%$ of clay, while these values decrease to 0.36 and 0.45 for the 3 and $7 \mathrm{wt} \%$ and $5 \mathrm{wt} \%$ hybrid samples.

Concerning the $X_{\beta}$ value, its contribution reaches the highest value in the sample with $7 \mathrm{wt} \%$ of Na-MMT. However, it was observed that the peak related to $\beta$-crystalline disappeared in $7 \mathrm{wt} \% \mathrm{Na}-\mathrm{MMT} / 5 \mathrm{wt} \%$ PAfs. The diminution $X_{\gamma}$ and $X_{\beta}$ values in hybrid composites can be explained by the presence of polyamide fibers.

4.3. DSC Analysis. Figure 7 displays the DSC thermographs of t-PAfs/PP composite, f-Na-MMT/PP nanocomposites, and hybrids. The DSC results are displayed in Table 3. The degree of crystallinity of PP and different composites was determined according to (3), in which $\Delta H_{m}$ is the melting enthalpy of PP and $\Delta H_{m}{ }^{0}$ presents the heat of fusion of $100 \%$ crystalline polypropylene, at the equilibrium melting point, $T^{0}{ }_{m}=187.5^{\circ} \mathrm{C}$. A literature value of $207.33 \mathrm{~J} / \mathrm{g} \Delta H_{m}{ }^{0}$ was used (Wunderlich [37]):

$$
\frac{\Delta H_{m}}{\Delta H_{m}^{100 \%}}
$$

However, in the present study, the degree of crystallinity was determined with the application of a correction factor in order to take into consideration the amount of fillers (PAfs and Na-MMT) in different composites. Thus, accurate values of $\chi_{c}$ reported were obtained from the following equation, where $\left(w_{f}\right)$ corresponds to the weight percentage of fillers in the composite:

$$
\frac{\Delta H_{m}}{\Delta H_{m}^{100 \%}} \times \frac{100}{100-w_{f}} .
$$

It can be seen in Figures 7 and 8 and Table 3 that the melting temperatures of different composites are about $159^{\circ} \mathrm{C}$, slightly lower than $161^{\circ} \mathrm{C}$ of pure PP. the melting temperatures of $\mathrm{f}-\mathrm{Na}$ $\mathrm{MMT} / \mathrm{PP}$ increased slightly with increasing of $\mathrm{f}-\mathrm{Na}-\mathrm{MMT}$ amount. However, in the case of hybrid composites, in which $5 \mathrm{wt} \%$ of $\mathrm{t}$-PAfs was added to 3,5 , and $7 \mathrm{wt} \% \mathrm{f}-\mathrm{Na}-\mathrm{MMAT} / \mathrm{PP}$ nanocomposites, a constant value of melting temperature is observed that is almost between the melting temperature of t-PAfs/PP composite and different nanocomposites. The crystalline peak temperature $(T c)$ of the pure PP is increased slightly with $5 \mathrm{wt} \%$ t-PAfs. Meanwhile, Tc is increased significantly with different $\mathrm{f}-\mathrm{Na}-\mathrm{MMT} / \mathrm{PP}$ nanocomposites and hybrids. MMT and t-PAfs act as nucleating agents, which 

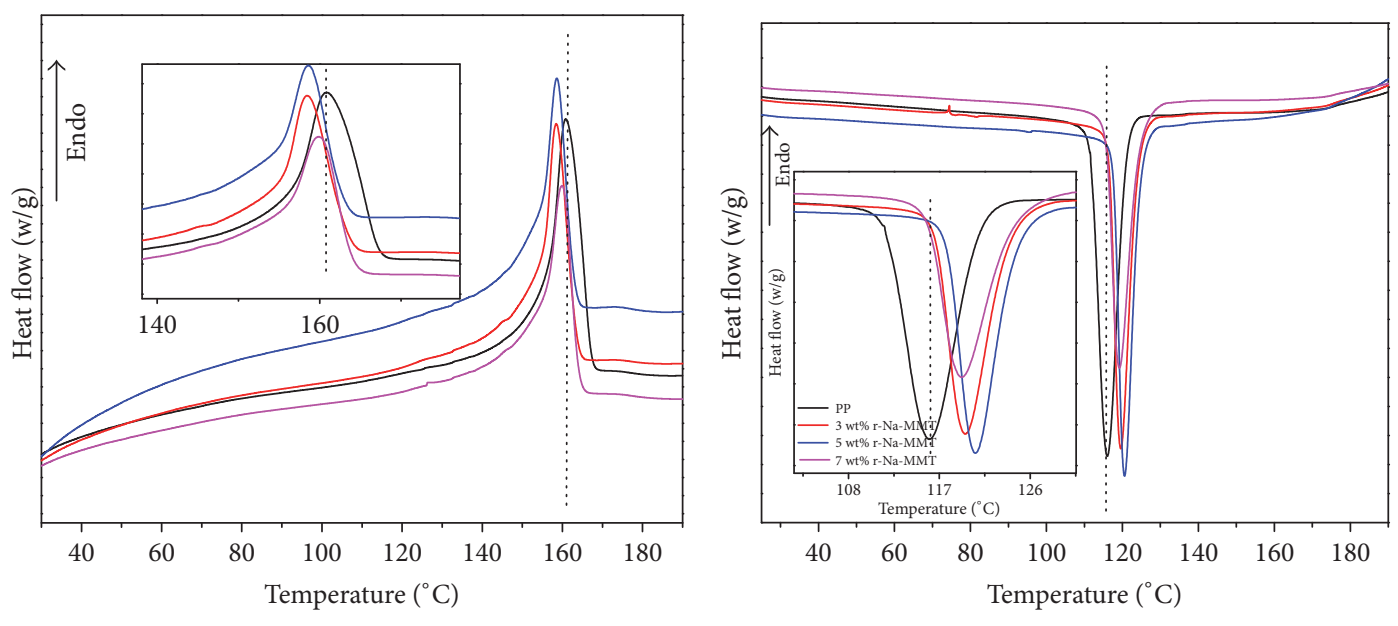

- PP
-3 wt $\%$ f-Na-MMT
-5 wt $\%$ f-Na-MMT

$7 \mathrm{wt} \%$ f-Na-MMT

- PP

_ 7 wt $\%$ f-Na-MMT

3 wt $\%$ f-Na-MMT

- $5 \mathrm{wt} \% \mathrm{f}-\mathrm{Na}$-MMT

(a)
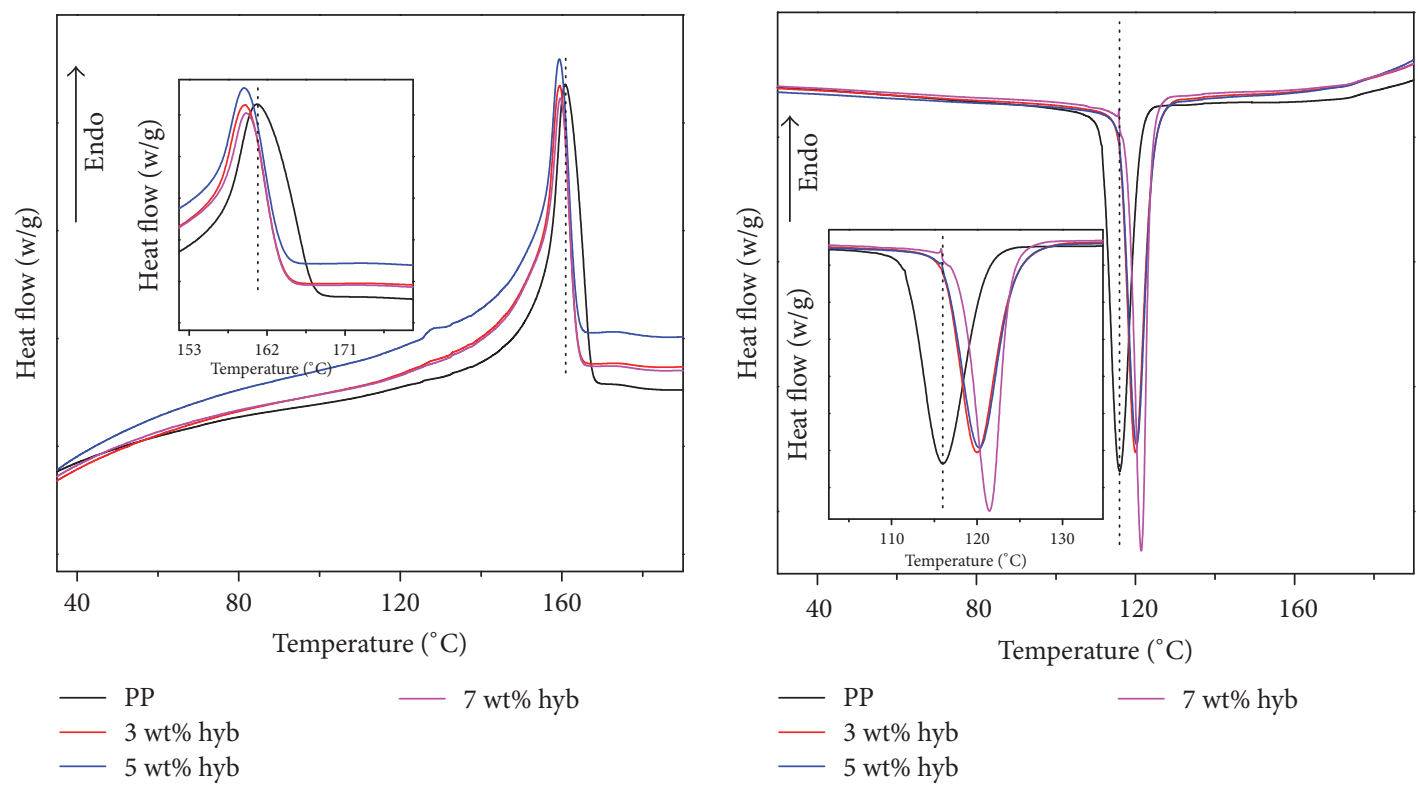

(b)

FIGURE 8: DSC thermographs of second heating and cooling runs of (a) f-Na-MMT/PP nanocomposite and (b) t-PAfs/f-Na-MMT/PP hybrid composites.

increase the crystallization temperature of $\mathrm{PP}$ matrix. The addition of $5 \mathrm{wt} \% \mathrm{t}$-PAfs to $7 \mathrm{wt} \% \mathrm{f}-\mathrm{Na}-\mathrm{MMT} / \mathrm{PP}$ nanocomposite increased $T c$ by up to $4^{\circ} \mathrm{C}$ compared to $5 \mathrm{wt} \%$ tPAfs/PP composite. This result indicates that the nucleating effect of MMT was further strengthened by the addition of polyamide fibers.

4.4. Optical and Scanning Electron Microscopy. To show the matrix/fiber adhesion and hybrid composite morphology, polarized optical microscopy (POM) and scanning electron microscopy (SEM) investigations were used. The
POM images of $5 \mathrm{wt} \% \mathrm{t}$-PAfs/PP composite and $5 \mathrm{wt} \% \mathrm{f}$ Na-MMT/5 wt\% t-PAfs/PP hybrid composite are shown in Figure 9. The polyamide fibers generally seem to be well dispersed. Also, some agglomerations were observed (see Figure 9(a)). Figure 9(b) shows the POM image of hybrid composite in which a good dispersed polyamide fiber was shown and with less agglomeration than t-PAfs/PP composite due to the presence of Na-MMT in the matrix. Length reduction of fibers was observed that can be explained by the effect of the intense shearing involved in the closed chamber of the Brabender plastograph. 


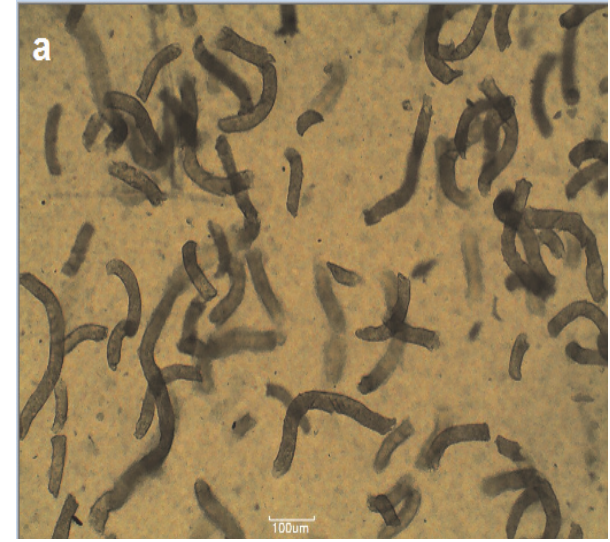

(a)

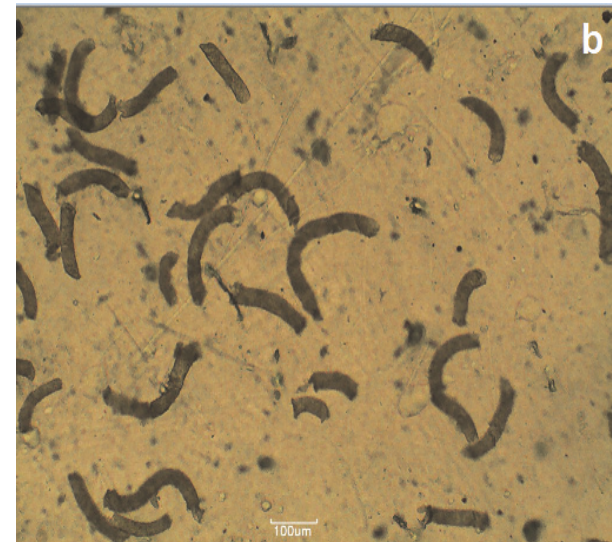

(b)

Figure 9: Optical micrographs of (a) $5 \mathrm{wt} \% \mathrm{t}-\mathrm{PAfs} / \mathrm{PP}$ composite and (b) $5 \mathrm{wt} \% \mathrm{t}-\mathrm{PAfs} / 5 \mathrm{wt} \% \mathrm{f}-\mathrm{Na}-\mathrm{MMT} / \mathrm{PP}$ hybrid composite.

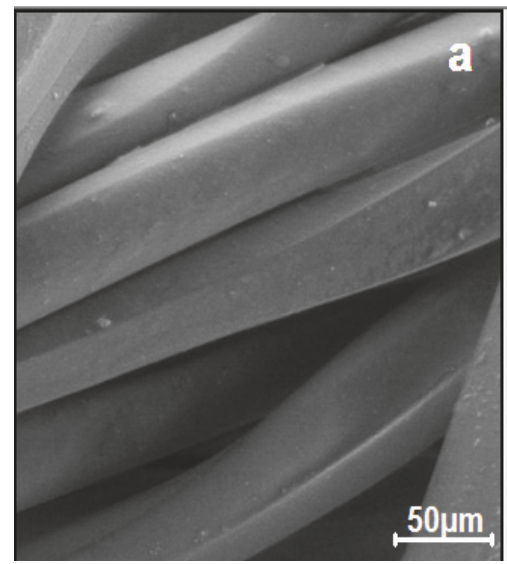

(a)

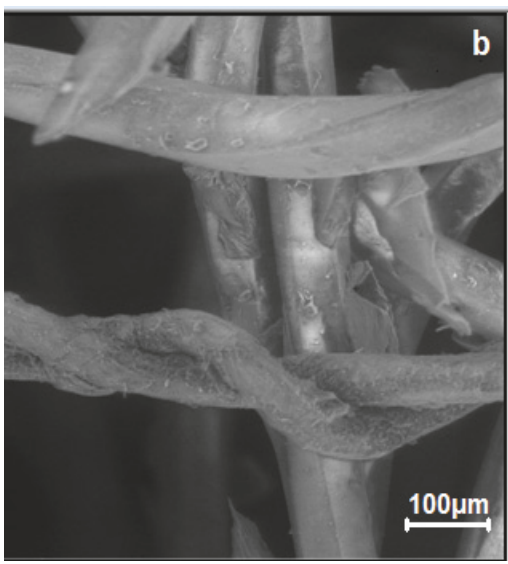

(b)

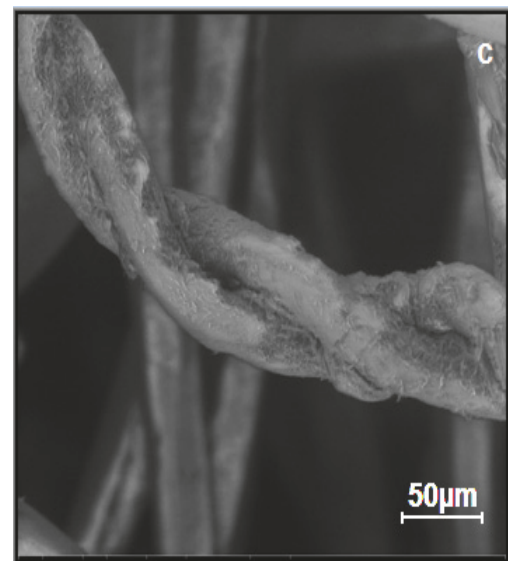

(c)

FIGURE 10: SEM micrographs of (a) untreated PAfs and (b, c) treated PAfs.

Scanning electron micrographs (SEM) of untreated and treated polyamide fibers PAfs are shown in Figure 10. It can be observed that the untreated fibers showed a smooth surface while the images of treated surface polyamide fibers exhibit rough surfaces, which proved the effect of the treatment.

Scanning electron micrographs of the tensile fractured surface of $5 \mathrm{wt} \%$ PAfs/PP composite and $5 \mathrm{wt} \% \mathrm{t}-\mathrm{PAfs} / 5 \mathrm{wt} \%$ f-Na-MMT/PP hybrid composite are shown in Figure 11. Figures 11(a) and 11(b) show the SEM micrographs of $5 \mathrm{wt} \%$ PAfs/PP and $5 \mathrm{wt} \%$ t-PAfs/PP composites, respectively. For the composite based on untreated polyamide fibers, fibers pull-out, the absence of polymer attached to the fiber surface, and fiber fracture clearly indicate a very limited adhesion between PP and fibers (Figure 11(a)). On the other hand, in the case of t-PAfs/PP composite, fibers pull-out and debonding reduced significantly and the adhesion between fiber and matrix improved strongly. In addition, it was observed that the fibers folded with no fiber pull-out after tensile test what confirm that the interfacial adhesion of the treated fiber composites is much better than that of the untreated fiber composite.
Figures 11(c) and 11(d) show the SEM micrographs of the tensile fractured surface and the stretched surface of hybrid composite. It can be observed from the micrograph Figure 11(c) that the addition of t-PAfs in Na-MMT/PP nanocomposite gives rise to a good interfacial adhesion which can be confirmed by the few voids appearing in the surface of stretched tensile specimen shown in Figure 11(d).

\section{Conclusions}

From the obtained results by different experimental methods, the following conclusions can be summarized. The reactive melt mixing method using the functionalizing agent successfully gives rise to a total or partial exfoliation with $5 \mathrm{wt} \%$ of $\mathrm{f}-\mathrm{Na}-\mathrm{MMT}$ as has been proven with FTIR and WAXS results. The t-PAfs can be effectively incorporated in $\mathrm{f}-\mathrm{Na}-\mathrm{MMT} / \mathrm{PP}$ recycled nanocomposite matrix. The differential scanning calorimetry (DSC) measurements indicate the nucleating effect of f-Na-MMT and t-PAfs. The treatment of polyamide fiber surface with stearic acid is a simple and a successful method that enhances the adhesion with the f-Na-MMT/PP 


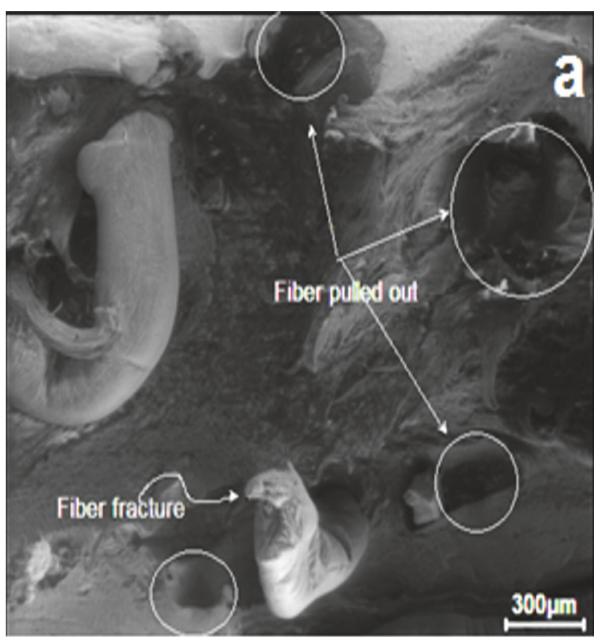

(a)

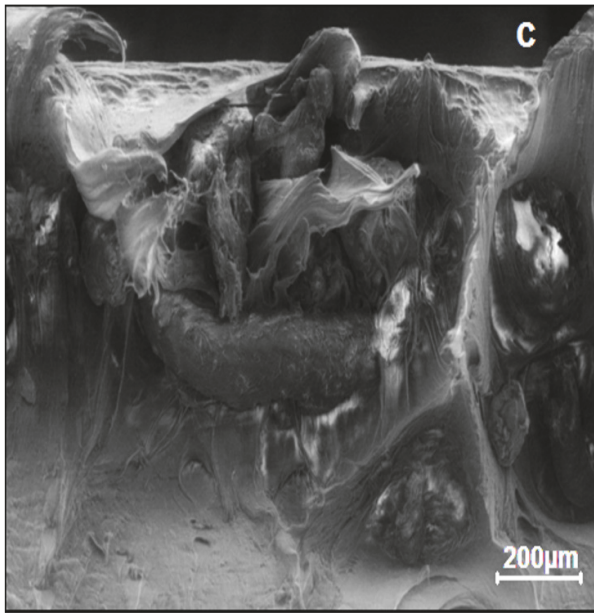

(c)

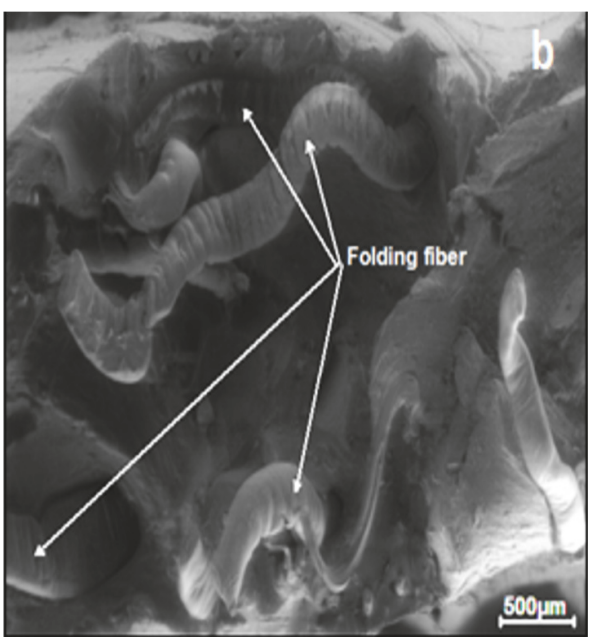

(b)

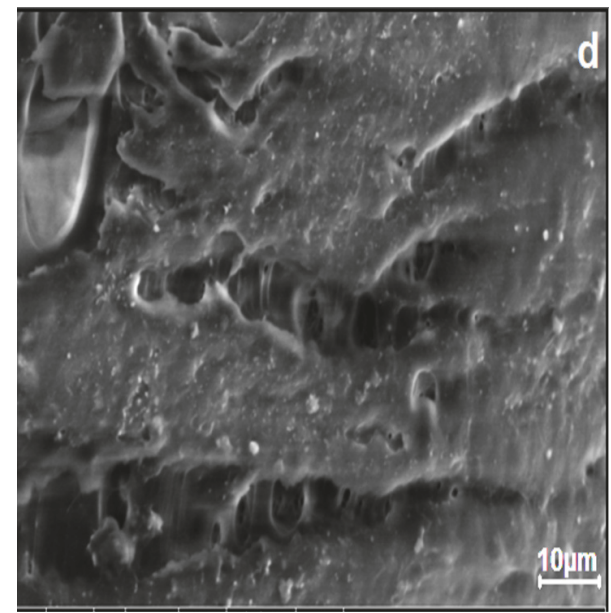

(d)

Figure 11: SEM micrographs of the tensile fractured surface of (a) $5 \mathrm{wt} \%$ PAfs/PP composite, (b) $5 \mathrm{wt} \% \mathrm{t}$-PAfs/PP composite, (c) $5 \mathrm{wt} \%$ $\mathrm{t}-\mathrm{PAfs} / 5 \mathrm{wt} \% \mathrm{f}-\mathrm{Na}-\mathrm{MMT} / \mathrm{PP}$ hybrid composite, and (d) the tensile stretched surface of hybrid composite.

recycled nanocomposite. A good dispersion of the fibers with a noticeable improvement of the interfacial adhesion between PP and treated PAfs phases was observed.

\section{Conflicts of Interest}

The authors declare that there are no conflicts of interest regarding the publication of this paper.

\section{References}

[1] R. A. Weiss, "Mechanical properties of polypropylene reinforced with short graphite fibers," Polymer Composites, vol. 2, no. 3, pp. 95-101, 1981.

[2] S. Pavlidou and C. D. Papaspyrides, "A review on polymerlayered silicate nanocomposites," Progress in Polymer Science, vol. 33, no. 12, pp. 1119-1198, 2008.

[3] J. I. Velasco, J. A. De Saja, and A. B. Martínez, "Crystallization behavior of polypropylene filled with surface-modified talc,"
Journal of Applied Polymer Science, vol. 61, no. 1, pp. 125-132, 1996.

[4] W. Qiu, K. Mai, and H. Zeng, "Effect of silane-grafted polypropylene on the mechanical properties and crystallization behavior of Talc/polypropylene composites," Journal of Applied Polymer Science, vol. 77, no. 13, pp. 2974-2977, 2000.

[5] M. M. Thwe and K. Liao, "Durability of bamboo-glass fibre reinforced polymer matrix hybrid composites," Composites Science and Technology, vol. 63, no. 3-4, pp. 375-387, 2003.

[6] A. K. Rana, A. Mandal, B. C. Mitra, R. Jacobson, R. Rowell, and A. N. Banerjee, "Short jute fiber-reinforced polypropylene composites: effect of compatibilizer," Journal of Applied Polymer Science, vol. 69, no. 2, pp. 329-338, 1998.

[7] P. K. Mallick, Fiber Reinforced Composites Materials. Manufacturing, and Design, Taylor and Francis group, Boca Raton, London, UK, 3rd edition, 2007.

[8] S. Jiang, Q. Li, Y. Zhao, J. Wang, and M. Kang, "Effect of surface silanization of carbon fiber on mechanical properties of carbon fiber reinforced polyurethane composites," Composites Science and Technology, vol. 110, pp. 87-94, 2015. 
[9] M. J. John, C. Bellmann, and R. D. Anandjiwala, "Kenafpolypropylene composites: effect of amphiphilic coupling agent on surface properties of fibres and composites," Carbohydrate Polymers, vol. 82, no. 3, pp. 549-554, 2010.

[10] O. M. L. Asumani, R. G. Reid, and R. Paskaramoorthy, “The effects of alkali-silane treatment on the tensile and flexural properties of short fibre non-woven kenaf reinforced polypropylene composites," Composites Part A: Applied Science and Manufacturing, vol. 43, no. 9, pp. 1431-1440, 2012.

[11] N. Chand and U. K. Dwivedi, "Effect of coupling agent on abrasive wear behaviour of chopped jute fibre-reinforced polypropylene composites," Wear, vol. 261, no. 10, pp. 1057-1063, 2006.

[12] M. Prakash and G. Pravin, "The effect of coupling agent on the properties of short non-woven PET micro fiber reinforced polypropylene (PP) composites," International Journal of Chemical, Environmental and Biological Sciences, vol. 2, pp. 23204087, 2014.

[13] W. S. Chow and Z. A. Mohd Ishak, "Mechanical, morphological and rheological properties of polyamide 6/organomontmorillonite nanocomposites," Express Polymer Letters, vol. 1, no. 2, pp. 77-83, 2007.

[14] G. Gorrasi, M. Tortora, V. Vittoria, G. Galli, and E. Chiellini, "Transport and mechanical properties of blends of $\operatorname{poly}(\varepsilon-$ caprolactone) and a modified montmorillonite-poly( $\varepsilon$-caprolactone) nanocomposite," Journal of Polymer Science Part B: Polymer Physics, vol. 40, no. 11, pp. 1118-1124, 2002.

[15] A. Okada and A. Usuki, "Twenty years of polymer-clay nanocomposites," Macromolecular Materials and Engineering, vol. 291, no. 12, pp. 1449-1476, 2006.

[16] E. P. Giannelis, "Polymer layered silicate nanocomposites," Advanced Materials, vol. 8, no. 1, pp. 29-35, 1996.

[17] P. Reichert, H. Nitz, S. Klinke, R. Brandsch, R. Thomann, and R. Mülhaupt, "Poly(propylene)/organoclay nanocomposite formation: influence of compatibilizer functionality and organoclay modification," Macromolecular Materials and Engineering, vol. 275 , no. 1, pp. 8-17.

[18] M. Kawasumi, N. Hasegawa, M. Kato, A. Usuki, and A. Okada, "Preparation and mechanical properties of polypropylene-clay hybrids," Macromolecules, vol. 30, no. 20, pp. 6333-6338, 1997.

[19] M. Kato, A. Usuki, and A. Okada, "Synthesis of polypropylene oligomer-clay intercalation compounds," Journal of Applied Polymer Science, vol. 66, no. 9, pp. 1781-1785, 1997.

[20] D. H. Kim, P. D. Fasulo, W. R. Rodgers, and D. R. Paul, "Structure and properties of polypropylene-based nanocomposites: effect of PP-g-MA to organoclay ratio," Polymer Journal, vol. 48, no. 18, pp. 5308-5323, 2007.

[21] A. Usoki, M. Kato, A. Okada, and T. Kurauchi, "Synthesis of polypropylene-clay hybrid," Journal of Applied Polymer Science, vol. 63, no. 1, pp. 137-139, 1997.

[22] S. Bouhelal, US patent, No. 7,517,942, 2009.

[23] S. Bouhelal, patent, No. 7,550,526, 2009.

[24] S. Bouhelal, M. E. Cagiao, S. Khellaf et al., "Nanostructure and microechanical properties of reversibly crosslinked isotactic polypropylene/clay composites," Journal of Applied Polymer Science, vol. 115, no. 5, pp. 2654-2662, 2010.

[25] S. Bouhelal, M. E. Cagiao, D. Benachour et al., "SAXS study applied to reversibly crosslinked isotactic polypropylene/clay nanocomposites," Journal of Applied Polymer Science, vol. 117, no. 6, pp. 3262-3270, 2010.
[26] R. Eslami-Farsani, S. M. Reza Khalili, Z. Hedayatnasab, and N. Soleimani, "Influence of thermal conditions on the tensile properties of basalt fiber reinforced polypropylene-clay nanocomposites," Materials and Corrosion, vol. 53, pp. 540-549, 2014.

[27] M. S. Chowdary and M. S. R. N. Kumar, "Effect of nanoclay on the mechanical properties of polyester and s-glass fiber (Al)," International Journal of Advanced Science and Technology, vol. 74, pp. 35-42, 2015.

[28] K. Majeed, M. Jawaid, A. Hassan et al., "Potential materials for food packaging from nanoclay/natural fibres filled hybrid composites," Materials and Corrosion, vol. 46, pp. 391-410, 2013.

[29] M. Pracella, D. Chionna, I. Anguillesi, Z. Kulinski, and E. Piorkowska, "Functionalization, compatibilization and properties of polypropylene composites with Hemp fibres," Composites Science and Technology, vol. 66, no. 13, pp. 2218-2230, 2006.

[30] H. Ku, H. Wang, N. Pattarachaiyakoop, and M. Trada, "A review on the tensile properties of natural fiber reinforced polymer composites," Composites Part B: Engineering, vol. 42, no. 4, pp. 856-873, 2011.

[31] K. H. Prasad and M. S. Kumar, "Thermal Characterization of PP/Na+-MMT Composite Materials," Journal of Materials Science and Engineering, vol. 5, pp. 80-86, 2011.

[32] F. Zouai, S. Bouhelal, M. E. Cagiao, F. Z. Benabid, D. Benachour, and F. J. B. Calleja, "Study of nanoclay blends based on poly(ethylene terephthalate)/poly(ethylene naphthalene 2,6dicarboxylate) prepared by reactive extrusion," Journal of Polymer Engineering, vol. 34, no. 5, pp. 431-439, 2014.

[33] E. P. Giannelis, R. Krishnamoorti, and E. Manias, "Polymersilicate nanocomposites: Model systems for confined polymers and polymer brushes," Advances in Polymer Science, vol. 138, pp. 108-147, 1999.

[34] L. E. Alexander, X-ray diffraction methods in Polymer Science, vol. 19, Wiley, New York, NY, USA, 2nd edition, 1969.

[35] A. T. Jones, J. M. Aizlewood, and D. R. Beckett, "Crystalline forms of isotactic polypropylene," Die Makromolekulare Chemie, vol. 75, no. 1, pp. 134-158, 1964.

[36] P. H. Nam, P. Maiti, M. Okamoto, T. Kotaka, N. Hasegawa, and A. Usuki, "A hierarchical structure and properties of intercalated polypropylene/clay nanocomposites," Polymer Journal, vol. 42, no. 23, pp. 9633-9640, 2001.

[37] B. Wunderlich, Macromolecular Physics, vol. 3, Academic Press, New York, NY, USA, 2nd edition, 1980. 

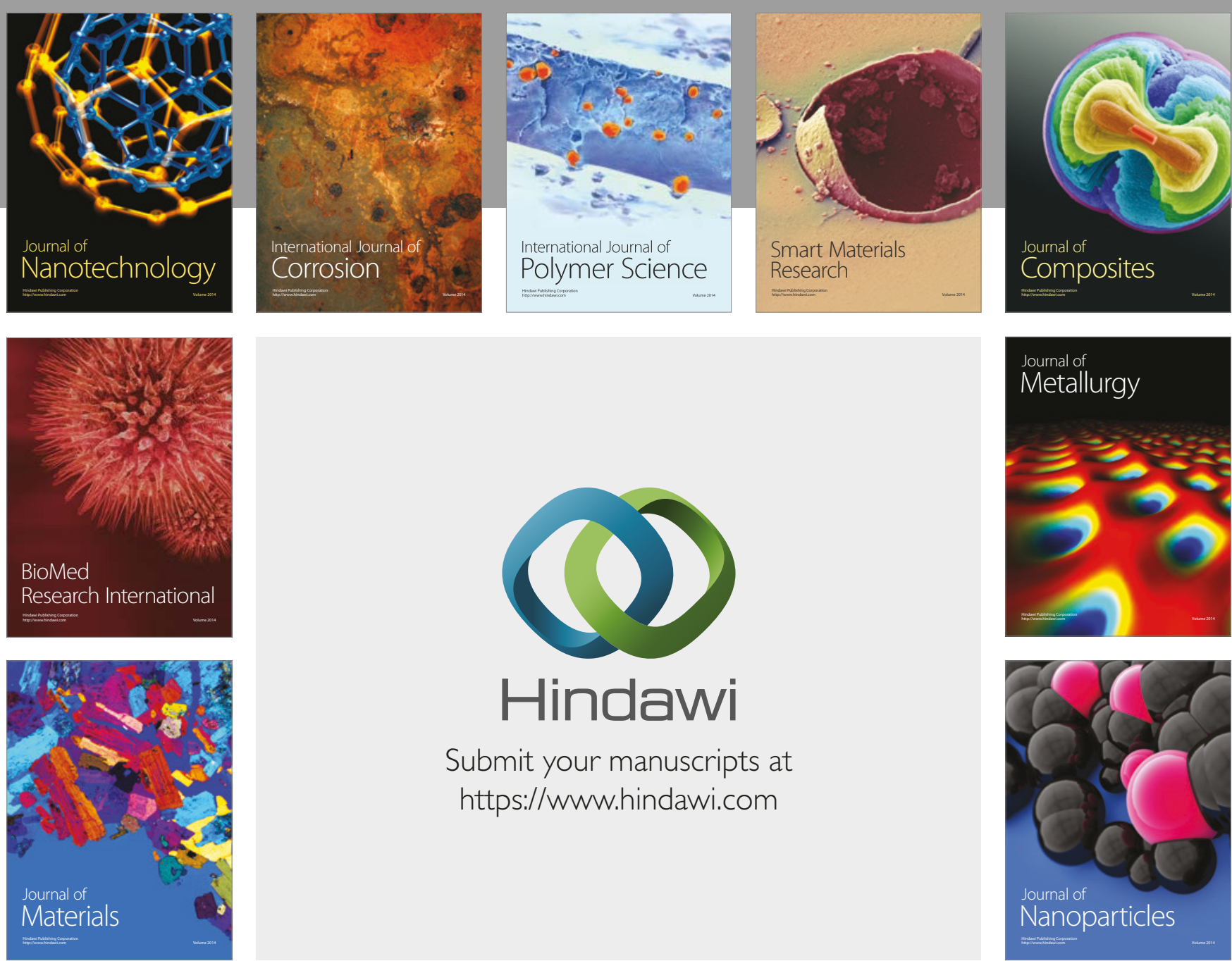

\section{Hindawi}

Submit your manuscripts at

https://www.hindawi.com
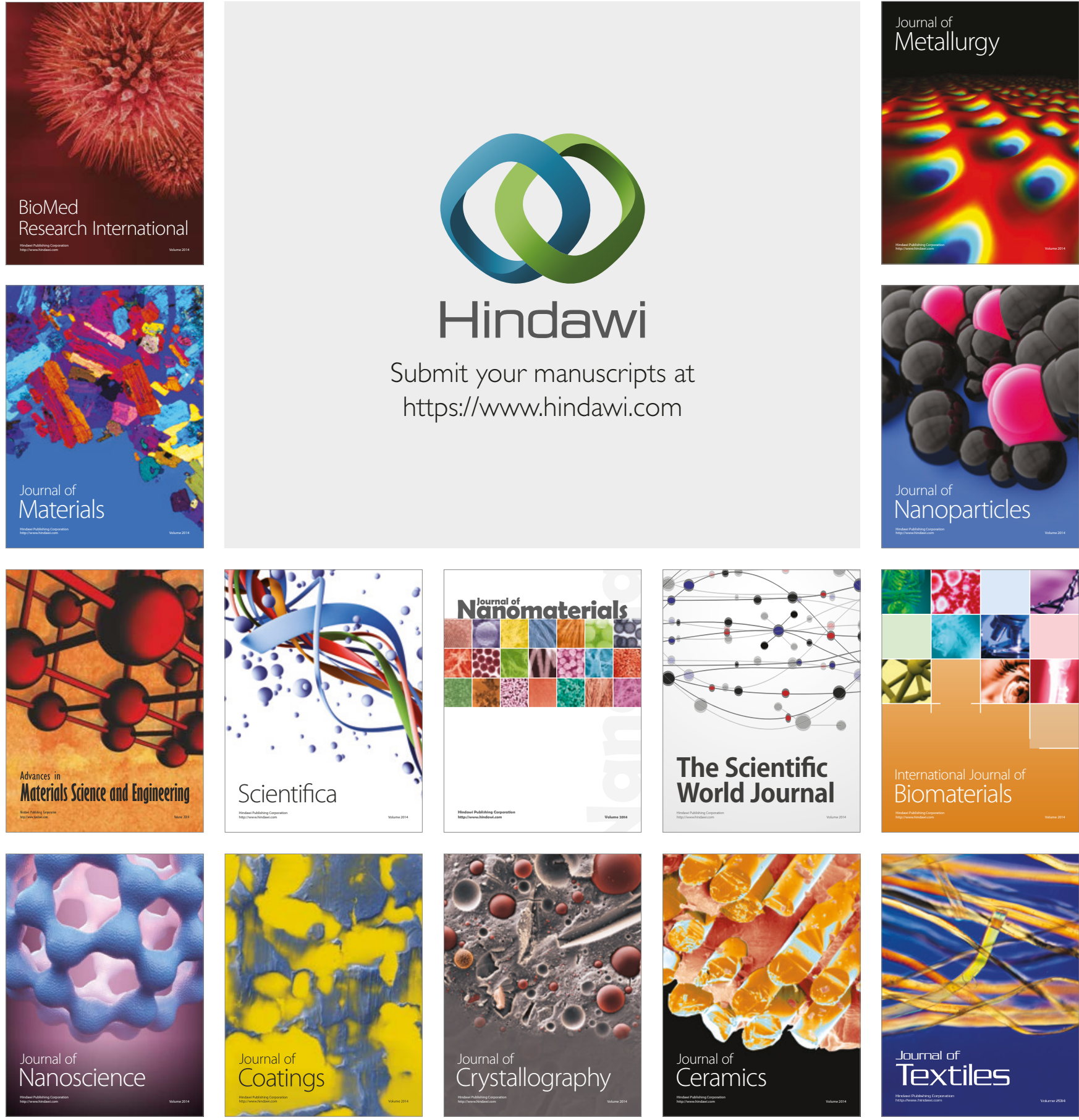

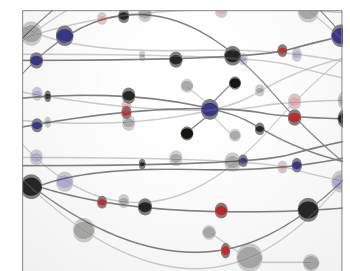

The Scientific World Journal
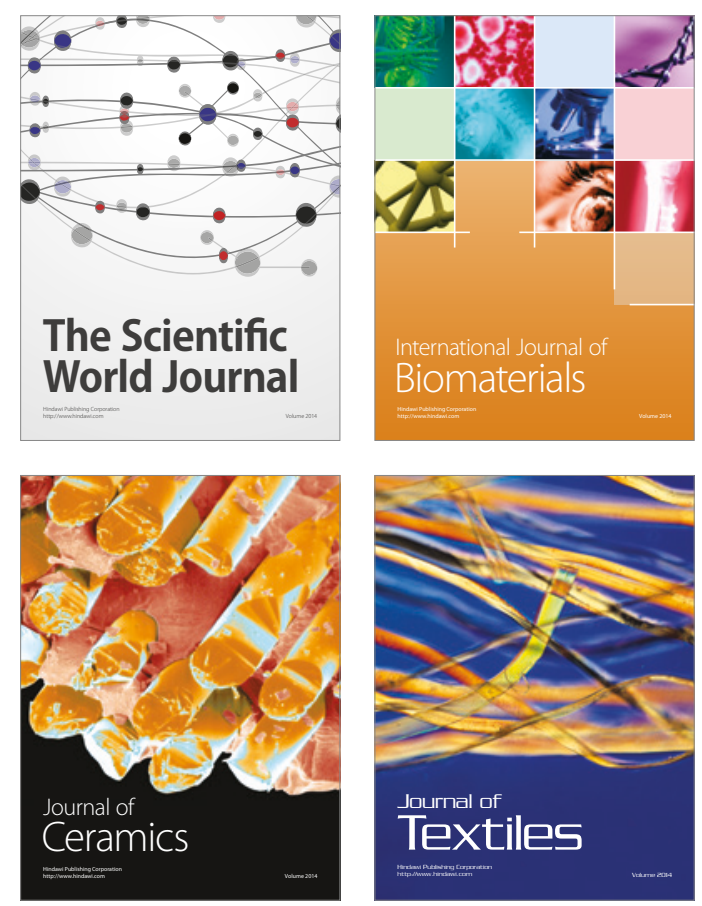